\title{
Language at home and the school: Resistance and compromise
}

\begin{tabular}{|c|c|}
\hline $\begin{array}{c}\text { Birut Zemits } \\
\text { Charles Darwin University } \\
\text { birut.zemits@cdu.edu.au }\end{array}$ & $\begin{array}{c}\text { Melanie Mullins } \\
\text { Charles Darwin University }\end{array}$ \\
\hline \multicolumn{2}{c|}{ Therese Parry } \\
Charles Darwin University
\end{tabular}

Keywords: Indigenous education; Indigenous languages; initial teacher education

\begin{abstract}
When a bilingual or multilingual person lives in a country where the national language dominates, many adjustments need to be made from one context to another. This is especially true when people whose first language is not English, are required to participate in Australian schools using the English language. To better understand some of the dynamics that occur for an individual in this transition, the authors background the situation and then give a personal recount of their experiences of moving between one language context to another. The purpose of this article is to explore some of the complexities of moving between the language of home and community and the demands of standard Australian English in the Indigenous student's school. It suggests that the resistance to fully adopting the colonising, dominant language of English, varies from one individual to another. Those that succeed in the dominant system have adopted a measure of compromise for their benefit and for the benefit of the community in which they live.
\end{abstract}

\section{Background}

With the march of global languages dominating ways people communicate, Indigenous languages are undeniably under threat in Australia since English has become the principal means of communication through the media, in institutions and in most areas for daily life in the dominant cultural milieu. The Second National Indigenous Languages Survey found that only 13 of the originally identified 250 Australian Indigenous languages are still spoken in a 'strong' way; where there are a relatively large number of speakers across all age groups (Marmion, Obata, \& Troy, 2014, p. xii). Government education policies have waxed and waned with respect to supporting language maintenance and revival in school in the Northern Territory (NT). This has often been to the detriment of ongoing support for Indigenous language teaching, in spite of clear evidence to support the value of teaching literacy in the child's first language (Devlin, Disbray, \& Devlin, 2017; Devlin, 2009; Disbray, 2014). This rocky history of bilingual education means that in 2018, the language of the home is rarely the language of instruction in the school, despite the first language's dominance in a community (McKay, 2017). The challenges for individuals developing strategies to maintain their own language(s) are in part reliant on these external factors.

Many individuals in communities in the Northern Territory want to hold onto one or more Aboriginal languages. The school is a place where staff and students come into a complex interaction about language maintenance and use. Within this domain, there are particular challenges faced by bilingual and multilingual Aboriginal Teaching Assistants as a move is made from the languages used with students when out in the community in which they live, to the expectations of Standard Australian English (SAE) as taught in the school. Members of the community may have a strong resistance to the imposed standard English, which depletes and diminishes the importance of an Indigenous community language. However, the pressure to maintain progression using the national curriculum (Australian Curriculum Assessment and Reporting Authority, 2018) alongside national testing regimes (Australian Curriculum, 2011), make it difficult to prioritise the community language for teaching, especially when the NT Education Department 
does not support bilingual delivery of lessons.

In the NT, an Aboriginal Teaching Assistant (TA) needs to traverse these complex domains of communication. As trainee teachers in the Growing Our Own program, they develop strength by understanding how government policies can impact school cultures, yet they are still embedded in a system that may not understand the language pressures they experience. The ideology that a classroom teacher holds in relation to bilingualism and diverse language use can seriously impact the possibilities for students in the classroom. Freeman (cited in Henderson, 2017, p. 22) suggests that the challenge is to shift ideology and teacher language expectations together with a change in overarching policies.

\section{Nauiyu community}

Communities such as Nauiyu on the Daly River (approximately 220 kilometres south west of Darwin) have survived through the strong values linked to a sense of belonging and community responsibility (Ungunmerr, 1988). The community has maintained cultural values in spite of many interventions through colonising actions (Remote Area Health Corps, 2010) and extensive incursions into the underpinning values and beliefs of a traditional way of life (Rose, 2005). Projects such the CSIRO Indigenous language calendar and plant identification, representing many of the Daly River languages including Ngan'gi, MalakMalak, Matngaala and Wagiman (CSIRO, 2017), have highlighted the diversity of linguistic influences in the community. These differences can be attributed to the Catholic mission, established in 1956, which drew together ten different language groups from the area as land was sold to farming interests. Traditional languages such as Ngan'gi are diminishing and most community members use Aboriginal English to discuss everyday events and life.

There is a disconnection between the languages used at home and in the school. Aboriginal English is the community language children predominantly use in St Francis Xavier School at Nauiyu, although many also understand and speak one or two other languages with greater or lesser capacity. The school caters for students from pre-school to secondary and recognises the importance of addressing the needs of children for whom English may be a second, third or fourth language (Catholic Education, 2014). The principal language of instruction remains English and the non- Indigenous teachers seldom speak or understand community languages, although most can comprehend Aboriginal English. The reality in the community is that students are rarely exposed to standard Australian English other than through the teachers at the school, through media exposure and when they have interactions in the shop.

\section{The narrative of three voices}

Given the background, highlighted above, Indigenous students in a multilingual community require their teachers to develop a high level of empathy to understand the challenges they may have in learning the required Standard Australian English. The next part of this paper introduces the perspectives of three people speaking together about language maintenance and use in the community while they worked on completing university assignments. Two of the voices are from Melanie Mullins and Therese Parry who have lived most of their lives at Nauiyu and are embedded deeply in the school and the community. At the time of writing, they worked as Aboriginal Teaching Assistants at the St Francis Xavier School and were in their third year of a teaching degree. The third voice, Birut Zemits, is a lecturer from Charles Darwin University who has worked in the Growing Our Own program, delivering academic writing, studies about cultural intelligence, and language related units.

All three authors hope that their experiences resonate with readers and will help them to see how a belief in the value of other languages can be considered as front and centre of teaching and learning. The authors have chosen a personal narrative style to consider the issues and to highlight main points. These stories were shared at a panel presentation at the 2017 Australian Council for Adult Literacies Conference (Ober, Sefton-Rowston, Mullins, Parry, Oldfield, Willsher, \& Zemits, 2017) where audience members commented positively on the empathetic response they felt in identifying with this style of presentation. In writing, we have aimed to maintain this tone. The narrative started with the lecturer's voice and then we moved into a few themes while trying to maintain a conversational style for the benefit of the audience. 


\section{The narrative}

Birut: Over the three years I have been visiting the community to deliver units of study in the Catholic Education funded Growing our Own program, we have had many conversations about negotiating language use for learning in the academic study zone. Sometimes these conversations were related to assessment tasks, sometimes just as a topic of shared interest. My observations of the skill with which the teaching assistants shift from one mode of speaking to another in the classroom and in the playground, and their capacity to identify the differences, has impressed and fascinated me. This has made me reflect deeply on my own language learning experiences.

As a child in the migrant area of Cabramatta in Sydney, entering pre-school with no English was quite traumatic. There were no language specialists and the assimilationist policies of the time very much supported the 'swim or sink' method of immersion language learning. I recall being overwhelmed by voices making incomprehensible sounds and people expecting me to understand what they were saying. We were expected to play games with clear instructions but I understood next to nothing of what was said. A deep-seated memory is one of sitting under a yellow slippery-dip, crying in confusion. I also remember a young boy, Ronnie (a stutterer), who came to reassure me in words I could not understand, that 'it was all okay'. His warmth and empathy with my difficulties in communicating remain a strong memory fifty years later.

I learned the English language quite rapidly and have succeeded first as a school teacher and now in the university. Career and acceptance in the Australian mainstream culture meant a lot of adjustments. While I maintain the capacity to speak my mother's and father's languages, Latvian and Lithuanian, they have remained essentially separate from my working life. There were times in my life where I rarely spoke these languages and I still have to make a special effort to seek out people with whom to speak them. The danger of not doing this is that I would lose the capacity to speak them, even though they have remained strong living languages on the other side of the world since the fall of the Iron Curtain and have been reinstated as national languages in the Baltic countries. My own children only speak a little (though they understand more) and my grandchildren speak only a few words of my mother's and my father's tongue, as I assimilated so well and their father was a mono-lingual English speaker.

So, some people reading this may have experiences of language-use compromises similar to mine. What I think is interesting, in reflecting on my own story, is how other languages can survive and be maintained alongside academic English success. I work with students from all over the world who bring their motivation to learn English to their career aspirations, but these students' experiences are very different from those students in Indigenous communities who are immersed in another language and essentially have to learn academic English as a foreign language.

Now in their third year of a teaching degree, Therese and Melanie daily negotiate multiple languages in their community as well as needing to adjust their own English language use to succeed as university students and future teachers in the Catholic Education system. Let's start with the early years of exposure to formal school learning. Therese, can you share some of your experiences about this so we can develop a deeper understanding of what happened in your learning journey?

Therese: Talking about my life and learning journey as an Indigenous person when growing up, I have had the experience and richness of both my culture and western world. There were several languages spoken to me. Also, I wasn't always a permanent resident in Nauiyu. My Dad did odd jobs such as with civil constructions. When a job came up, we as a family would move to another community for a couple of months. When I went to school in Wadeye, I had the pleasure of learning the local language, Murrinhpatha. As children, we learn so quickly and we adapt. I didn't have any troubles when trying to speak another language. You find the rhythm and make the transition quite smoothly.

Returning to the classroom in Nauiyu, we rarely spoke Australian Standard English. It was based more around our own language/clan groups. Francis Xavier Catholic School was never a bilingual school. The reason for that is that there were a number of diverse languages spoken. These are Ngan'gikurunggurr, Ngan'giwumirri, Malak Malak, Marri Ngar, Marrithiyel Marramaninjsji, Marri Tjevin alongside Kriol, Aboriginal English and Standard Australian English. In those days (1980-1990), we never had year levels; we were put in our clan and homeland groups. There were two clan groups in each class with two 
Indigenous teachers who taught each group. By doing this, the clan children had a strong connection and a sense of belonging, as they were with their family. We learnt through a very formal "chalk \& talk" system. Bush trips out to the homelands of each clan group were built into the timetable. This enriched our knowledge of who we are, what language group we belong to, which dreaming is ours and which country belongs to us. It strengthened our knowledge of our culture and passed it down to the next generation, which was me at the time. I was able to get the hang of what was expected of me, because I could understand the language and context.

My teachers were non-Indigenous, but we had Indigenous aides who took care of the cultural aspects of my learning. They also interpreted the Standard English spoken in the classroom. It felt like a safety net. It was a mixture of western standard and Indigenous literacy. What about your experience, Melanie?

Melanie: It is similar to yours in a lot of ways. My cultural language and knowledge were important to me as a student and still are as an adult. It's a lifelong learning knowledge. I learnt culture at home from my grandmother and at school when it was in clan groups. As you said, the school at Nauiyu was grouped as language groups with an Indigenous clan group teacher in the early years. It made me feel proud to learn about the cultural knowledge and language, and I still use this knowledge as an adult.

In later years of primary school, I got a lot of information about English language and literacy. The teachers didn't understand my home language in class, so I had to separate the language and speak English to the teachers in class. I had to learn to code switch and speak one language for some conversations and another for different situations. The teachers didn't understand the shift in my literacy needs. I often felt uncomfortable and didn't want to get involved in most lessons.

For high school, I went away to boarding school at St Johns in Darwin. I started to understand what English literacy is about. There, all my formal learning was in English. I was immersed in speaking, reading and writing English. I was surrounded by local Darwin students. Instead of waking up and listening to my family speaking my language, I went to breakfast and spoke English. This was like a literacy immersion program, but not really structured. My own awareness of my culture increased in relation to other cultures. At boarding school, I had to adjust to a strange place that I had never seen or heard of in my life. I found that the behaviour in the classroom at home was not quite as strict as it was living in the boarding house and going to school. I got used to this and managed to achieve in academic English. Tell us about your later experience learning English, Therese.

Therese: Like you Melanie, my middle years of schooling were quite different to being in community. This was because all the literacy demands were more in the western mode and genre. Initially, it was like what any student would go through. I felt nervous, anxious and unsure of what was expected of me. I found the boarding schools down south improved my literacy skills and exposed me to a different literary and cultural world. As a result, I would say I have the best of both worlds: my culture and the understanding of my English literary texts. I would not be able to undertake a teaching course at Charles Darwin University without the exposure and knowledge of the western genre.

Now, as a teacher in a school, a lot is still important for children about identity and belonging. It is important that Indigenous children have and know their identity. In our culture, our stories, dance, identity, and most important of all, the clan/homeland, plays a vital role in our lives. We have a sense of belonging that makes us who we are. Without these components in our culture we have nothing. As our mentor and local elder, who was once our school principal, Miriam Rose Baumann said, "Not knowing which clan, tribe or language group they belong to, it is like losing loved ones, like losing our language and identity" (Ungunmerr, 1988).

I do think it is important for children to have strong English skills too, so they can cope with the outside world. How we deal with diverse needs in the classroom is to have focused sessions where we present the formal English ideas in English. I see it is difficult for a lot of the children to use this formal language, but I try to model my own ability to switch from Aboriginal English to standard Australian English. We, as teaching assistants and university students, are constantly moving, or as our previous speaker, Robyn Ober says, "slipping and sliding" (Ober et al., 2017) between the community and academic languages. At school, we have a space where we go and often talk to each other in our language, just to regain our balance with our identity. Sometimes we speak our language in class, because that is what the children 
relate to the most, but this sometimes contradicts what the teacher wants. What do you think Melanie?

Melanie: During the ten years of being an Assistant Teacher at the Nauiyu School, I find that most nonIndigenous teachers are not from the Northern Territory and often from the big cities in different states. Many are unaware that in remote communities, life operates quite differently from western society. Some teachers see a pretty image of what our school or community looks like in their heads, but when they do come to our school, the picture is not what they have imagined and it is such a culture shock to them. Language barriers become difficult and teachers are frustrated when they are not able to communicate with the local students and teachers. I think that is why most teachers are not able to stay for long.

We try to keep our own language and culture going around these changes with each new teacher at the school. Our languages are shifting with the influences of media and the easy moving from place to place, but the common languages of children in the playground are still Aboriginal English, Kriol and some community languages. This has shifted a little since I went to school, but a lot is still the same for the community. The sad thing I find, is that we are losing students, as they are not able to understand what is required of them because of language difficulties. It's often too hard.

Therese: Yes, NAPLAN (Australian Curriculum, 2011) is often setting our Indigenous students up to fail, given the history of our students who clearly struggle. Our students find it just as difficult to make the cross-over in trying to speak Australian Standard English in a classroom as in an everyday situation. I would like to see greater acceptance of our students' languages in the school system. I hope that when we graduate as teachers, we have a chance to build understanding of language into our school curriculum. In doing so, the children in remote communities would understand a lot more and the nonIndigenous teachers would learn more from the Indigenous teachers.

Birut: Thank you so much for sharing your experiences and insights into the compromises and ideas of resistance relating to language use in academic learning and your own teaching. I think we can summarise the three main ideas in a conclusion.

\section{Conclusion}

This paper has reflected on experiences about language use and learning experienced by a university lecturer and two Indigenous student teachers. The introduction highlighted some of the historical factors that have impacted on the potential for classroom teaching in the local language. Author 2 noted the difficulties encountered in deciding on a language in Nauiyu when she was a student at the school, and the fact that Aboriginal English is the main language for communication today. Author 3 highlighted the importance of incoming teachers from other places acknowledging and showing respect for the children's lived language experience.

In a final list of suggestions, we would like to draw on three points, which echo the recommendations in the National Indigenous Languages Survey report (Marmion et al., 2014).

- Ensure that teachers coming to work in communities can empathise with the use of multiple languages and the practices of a community. This may be through pre-arrival training for that community.

- Extend language teaching practice based on evidence of what language activities work best for the interests of the community (Recommendation 2, Marmion et al., 2014).

- $\quad$ Aboriginal English speakers should be given support akin to bilingual language learning programs (Recommendation 8, Marmion et al., 2014).

We hope that our ideas resonate with the reader and that we have extended some discussion about improving this and other language learning and teaching situations in a way that may benefit and support Indigenous learners in the Northern Territory in the twenty-first century. 


\section{References}

Australian Curriculum. (2011). National Assessment Program Language and Numeracy (NAPLAN). Available at: https://nap.edu.au/naplan.

Australian Curriculum Assessment and Reporting Authority. (2018). English curriculum F-10. Available at: https://www.australiancurriculum.edu.au/f-10-curriculum/english/.

Catholic Education. (2014). St. Francis Xavier School, Nauiyu, Daly River. In: Northern Territory DoD (Ed). Darwin.

CSIRO. (2017). Indigenous seasons calendars. Available at: https://www.csiro.au/en/Research/ Environment/Land- management/Indigenous/Indigenous-calendars.

Devlin, B. (2009). Bilingual education in the Northern Territory and the continuing debate over its effectiveness and value. AIATSIS Research Symposium. Canberra.

Devlin, B., Disbray, S., \& Devlin, N.R.F. (2017). History of bilingual education in the Northern Territory: People, programs and policies. Singapore: Springer.

Disbray, S. (2014). At benchmark? Evaluating the Northern Territory Bilingual Education Program. In L. Gawne and J. Vaughan (Eds.). 44th Conference of the Australian Linguistics Society. Melbourne: University of Melbourne.

Henderson, K. (2017). Teacher language ideologies mediating classroom-level language policy in the implementation of dual language bilingual education. Linguistics and Education, 42: 21-33.

Marmion, D., Obata, K. \& Troy, J. (2014). Community, identity, wellbeing: the report of the Second National Indigenous Languages Survey. Canberra: Australian Institute of Aboriginal and Torres Strait Islander Studies.

McKay, G. (2017). The policy framework for bilingual education in Australian Indigenous languages in the Northern Territory. In B. Devlin, S. Disbray and N. Devlin (Eds). History of bilingual education in the Northern Territory: People, programs and policies. Singapore: Springer.

Ober, R., Sefton-Rowston, A., Mullins, M., Parry, T., Oldfield, J., Wllsher, M., \& Zemits, B. (2017). Language at home and in the academy: Resistance and compromise. In S. Shore (Ed).Traders, Neighbours and Intruders: Points of Contact. Darwin: Australian Council of Adult Literacy.

Remote Area Health Corps. (2010). Community Profile Daly River (Nauiyu). Available at: https://www. rahc.com.au/sites/default/files/documents/community_profiles/Daly River Community Profile.pdf.

Rose, D. B. (2005). An Indigenous philosophical ecology: Situating the human. Australian Journal of Anthropology, 16, 294-305.

Ungunmerr. M-R. (1988). Dadirri; Inner deep listening and quiet still awareness. A reflection by MiriamRose Unginmerr. Available at: http://www.miriamrosefoundation.org.au/about-dadirri. 